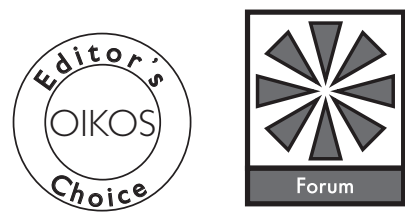

Oikos 122: 161-170, 2013

doi: $10.1111 / j .1600-0706.2012 .00066 . x$

(C) 2012 The Author. Oikos (C) 2012 Nordic Society Oikos

Subject Editor: Dustin Marshall. Accepted 18 October 2012

\title{
Predicting persistence in a changing climate: flow direction and limitations to redistribution
}

\author{
Cascade J. B. Sorte \\ C. J. B. Sorte (cjsorte@ucdavis.edu),Dept of Environmental, Earth and Ocean Sciences, Univ. of Massachusetts - Boston, 100 Morrissey Blvd., \\ Boston, MA 02125, USA.
}

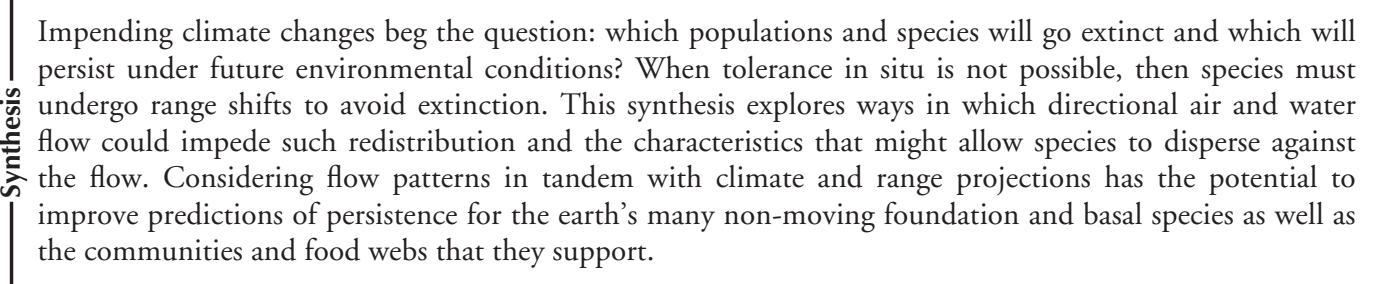

\begin{abstract}
Predicting which populations and species will persist (i.e. avoid extinction and continue to exist) in the face of climate change requires an understanding of mechanisms that allow species to cope with altered environmental conditions. When processes of tolerance, acclimation, and adaptation are insufficient to allow persistence in situ, redistribution is required for population or species persistence. Here, I review evidence that directional flows of water and air have the potential to restrict species' range boundaries under ambient conditions, the spread of introduced species, and the redistribution of native species under changing climatic conditions. I develop the hypothesis that flow patterns, such as the speed and directionality (i.e. poleward vs equatorward) of asymmetric air and water currents, may need to be considered when assessing the vulnerability of populations and species to climate change. To the degree that directional flows are found to limit redistribution, there may be disproportionate losses of diversity where the dominant flow direction opposes that of shifting climate space. Within this context, I highlight flow conditions and life-history traits that could help the most passively-dispersed species redistribute to track changing climate. These predictions merit further examination in order to better anticipate which populations, species, and associated communities are likely to persist under climate change.
\end{abstract}

Global climate change is altering environmental suitability across species' ranges (IPCC 2007a), and an increasing appreciation that ecosystem responses to climate change are complex and widespread (IPCC 2007b) has prompted a focus on understanding and predicting biological impacts (i.e. either negative or positive effects; Kintisch 2008). Some of the most negative impacts are the loss of diversity including genetic, species, and functional - that accompany extinctions. Whether populations and species will persist at the local and global scale, respectively, depends on their abilities to endure future climate shifts. The extinctions that have occurred to date (Pounds et al. 1999, Parmesan 2006) are minor in comparison to those predicted in the future: across 305 terrestrial and marine species, extinction probability by 2100 has been estimated as $10 \%$ and $14 \%$ based on model simulations and empirical observations, respectively (Maclean and Wilson 2011). As the rate of climate change continues to accelerate (IPCC 2007a), there needs to be an increasing focus on the underlying biological and location-specific characteristics that could allow species to avoid extinction (IPCC 2007b, Lawler 2009).

\section{Coping with climate change}

Species have a suite of mechanisms that allow them to cope with changes in climate, and the degree to which each of these is required for persistence depends on the magnitude of environmental alteration relative to the species' tolerance limits (Helmuth et al. 2005, Berg et al. 2010, Sorte et al. 2011). When changed conditions fall within species' current tolerance ranges (i.e. the range of conditions under which the population does not decline), no physiological or ecological modifications are immediately required for persistence. When environmental conditions fall outside of species' tolerance ranges, these physiological limits are likely to be expanded via acclimation (adjustments of traits that are phenotypically plastic and can change within an organism's lifetime) and/or adaptation (genetic changes requiring $1+$ generations) (Visser 2008). Whether adaptation can keep pace with environmental changes is still equivocal, and a growing number of studies show that rates of climate change can exceed adaptation abilities (Etterson and Shaw 2001, Jump and Peńuelas 2005, Parmesan 2006, 
Gienapp et al. 2008, Visser 2008). Especially where the mechanisms above (i.e. tolerance, acclimation and adaptation) are not sufficient to allow populations to persist, regional persistence may rely heavily on the process of redistribution (Helmuth et al. 2005).

Range shifts with climate change have already been documented for a number of species (Parmesan 2006, Sorte et al. 2010, Chen et al. 2011). Expansions in the poleward and upward directions have been most commonly reported (Helmuth et al. 2006, Parmesan 2006, Sorte et al. 2010); however, documentation of contractions at equatorward and low elevation range boundaries is increasing (Moritz et al. 2008, Jones et al. 2010), with even more contractions expected if there are lags in local extinctions (Anderson et al. 2009, Berestycki et al. 2009, Dullinger et al. 2012). These observations are verification that climate change can both present species with the opportunity for expansion of some range boundaries (i.e. into newly hospitable habitat) and force contraction of other range boundaries where in situ persistence becomes impossible (Jackson and Sax 2009).

In addition to highlighting the importance of redistribution to persistence, because it allows species to track changing climate conditions and, thus, maintain climate equilibrium, recent range shifts can also be indicative of location- and species-specific advantages and limitations to redistribution. For example, among the majority of plant species surveyed in the European Alps that have shifted their altitudinal ranges concurrent with climate warming (Lenoir et al. 2008), species with lighter seeds (which are more easily wind-dispersed) had faster rates of redistribution (Parolo and Rossi 2008). Similarly, model projections reported in Thomas et al. (2004) showed that when dispersal was limited, the number of predicted species-level extinctions increased by up to $250 \%$. Dispersal mode is, therefore, extremely important to redistribution ability, and the persistence of species that do not disperse actively - including many plants, algae, and invertebrates could be of particular concern.

Recent evidence suggests that extinction risk associated with flow-mediated dispersal limitation could be exacerbated under climate change. Here, I develop the hypothesis that for many species, an interaction between flow patterns and organismal characteristics will determine their abilities to redistribute and, thus, persist in the face of changing climate. In doing so, I identify gaps in the current literature and bring together predictions of specific flow conditions and species traits that could permit redistribution - particularly where dominant flow patterns do not parallel shifting climates - and themselves might be altered with climate change. By explicitly considering mechanisms of coping with changing climate and potential limitations to these processes, we will be poised to better predict future ecological patterns.

\section{Range limitation by dispersal and flow}

Whether flow patterns will limit redistribution under climate change depends partially on their importance in setting contemporary range boundaries. Species' range limits may be determined by one or multiple abiotic (e.g. temperature or water availability; Normand et al. 2009) or biotic factors (e.g. lack of a food source or presence of a dominant competitor; Gross and Price 2000). Dispersal limitation also plays a likely role for many species (Gaston 2009). Gaylord and Gaines (2000) showed that directional flow patterns can create dispersal barriers that define the boundaries of species' ranges and biogeographic provinces (i.e. locations of multiple species' range limits), and biogeographic breaks between marine provinces often occur at locations of discontinuities in water flow (Hayden and Dolan 1976). Flow limitation is particularly evident in marine systems: whereas dynamics of terrestrial plant systems can sometimes be described using models that incorporate only local-scale dispersal (Pacala et al. 1996), marine population models require incorporation of regionalscale processes due to the relative openness of marine populations (Roughgarden et al. 1988). However, recent studies in terrestrial systems have highlighted instances in which long-distance dispersal contributed significantly to gene flow and migration (Kinlan and Gaines 2003, Soons et al. 2004, McLachlan et al. 2005), indicating the potential for dispersal limitation to influence redistribution under climate change.

At the species level, however, there are few data on range-limiting factors, precluding quantification of the proportion of range boundaries set primarily by dispersal limitation. As an approximation, then, we can look to studies examining fitness parameters across species' ranges as indicators of range limiting factors because fitness is likely to decline near boundaries of species' ranges that are limited predominantly by climate or biotic conditions (Caughley et al. 1988). This approach could also help to discern climate from dispersal limitation in the many cases where both climate and flow discontinuities are coincident with species range limits (Gaylord and Gaines 2000). In a crosssystem review by Sexton et al. (2009), 1/3 of studies found no evidence of fitness declines at range margins, and a similar proportion of transplant experiments found no fitness declines for individuals transplanted beyond the current range, indicating that dispersal might be of primary importance in setting these species' range limits.

Dispersal limitation appears to be most important for limiting ranges of species that are relatively dependent on currents for dispersal (Wares et al. 2001). Again, estimating these values requires the use of reasonable proxies, in this case, the proportion of species with propagules known or assumed to have adaptations for dispersal in wind or water. Among studies of woody plants reviewed by Howe and Smallwood (1982), tree species adapted for wind dispersal ranged from approx. $30-40 \%$ and $3-46 \%$ in temperate and tropical forests, respectively; in the one study that included herbaceous and woody plants, $25-28 \%$ of species exhibited traits indicative of wind dispersal. Kinlan and Gaines (2003) report estimates of dispersal distance greater than $1 \mathrm{~km}$ for $21 \%$ of the 19 plant species and $77 \%$ of the 95 marine species. Therefore, compared to mobile species, for which dispersal is less flow-dependent (Bradbury and Snelgrove 2001), redistribution potential of a large number of plant and marine invertebrate species in an area may be largely determined by flow patterns.

The dispersal of species with propagules that are either completely non-moving or that move much slower than 


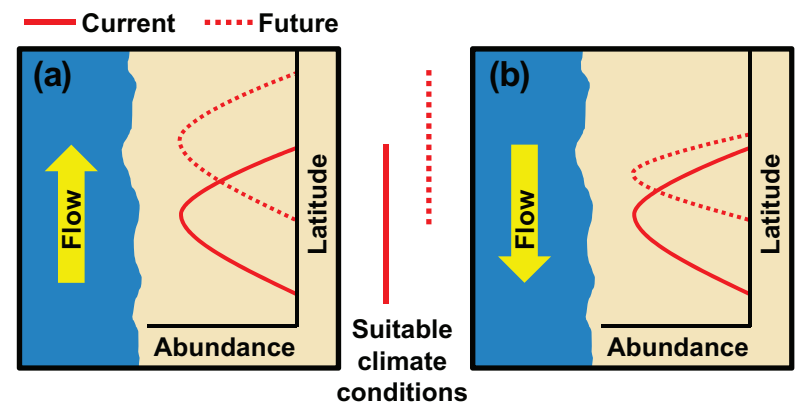

Figure 1. Effectiveness of redistribution as a mechanism of persistence under climate change could depend on flow direction. Along climate gradients, such as a temperature gradient across latitudes, (a) species that depend on flow patterns for dispersal might be better able to track suitable climate conditions when the direction of air or water flow (as shown here) parallels the direction of climate shifts. (b) However, when such shifts require upstream dispersal, lags in range shifts, contractions of species' ranges, and/or population declines may become more likely.

flow rates of air and water, their dispersal vehicles, may be strongly asymmetrical due to directional winds (Brown and Hovmøller 2002, Muñoz et al. 2004, Vanschoenwinkel et al. 2008) and water currents (Gilg and Hilbish 2003, Carson et al. 2011, Zardi et al. 2011). For these species, even in a stable climate, there exists a 'drift paradox', the incongruous persistence of populations in upstream locations despite dominant downstream flow (Müller 1982, Hershey et al. 1993). A number of studies have used analytical approaches to address the potential for population persistence in asymmetric flow (Speirs and Gurney 2001, Pachepsky et al. 2004, Byers and Pringle 2006, Lutscher et al. 2010) or in the situation of changing climatic conditions where the medium is static but appropriate habitat is shifting (Potapov and Lewis 2004, Berestycki et al. 2009). However, to my knowledge, there has not yet been an analytical study of the dual effects of directional flow and climate change, particularly which contrasts two broad scenarios: parallel versus non-parallel trajectories of flow and climate shifts (Fig. 1). The ability of species to not just maintain but shift their range boundaries upstream, which becomes a necessity with climate change, therefore depends on 1) the range-limiting factor (e.g. species that are already dispersal-limited should be more restricted by flow than those limited predominantly by climate) and 2) the strength of dispersal-limitation (e.g. the proportion of propagules dispersing upstream vs downstream).

\section{Redistribution limited by flow}

Flow-driven inhibition of spread has been shown for species whose ranges are not in equilibrium with their climate space, including non-native species spreading beyond their point of introduction. An example is the Mediterranean mussel Mytilus galloprovincialis, one of the most successful invasive species, which has colonized every continent except Antarctica and has a maximum estimated spread rate of $115 \mathrm{~km}$ year $^{-1}$ (Grosholz 1996, Kinlan and Gaines 2003). Four years after its introduction to South Africa in the late 1980s, M. galloprovincialis had spread up to $97 \mathrm{~km}$ along major current trajectories but less than $30 \mathrm{~km}$ in the direction contrary to the dominant currents (McQuaid and Phillips 2000). Similarly, asymmetric air flow appears to have slowed the spread of the wind-pollinated invasive cordgrass Spartina alterniflora in Washington, USA (Davis et al. 2004). Whereas pollen loads were high downwind of the established cordgrass meadow, they dropped precipitously at locations upwind of the meadow and local range boundary.

Native species are experiencing increasing disequilibrium with climate as shifts of these species' range boundaries lag behind changes in climatic conditions. Such lags can occur at either range boundary, with a lagged contraction (e.g. because individuals currently persist in that location even though population growth is negative) indicating an extinction debt and a lagged expansion indicating an immigration credit (Jackson and Sax 2009). The lag in species' range shifts can relate strongly to dispersal ability: for example, lags in poleward range shifts were greater for sedentary than mobile species of British butterflies (Warren et al. 2001). It is important to note, however, that lags in range expansions may be driven by myriad processes in addition to flow and dispersal limitation, including Allee effects, low habitat availability, or the influence of species interactions.

In most cases, the relative contributions of factors causing such lags are unknown; however, asymmetric flows have been shown to limit climate-driven redistribution of native species in some cases. To assess range shifts and limiting processes, Keith et al. (2011) used hindcasting techniques to project distributions of four marine invertebrate species in the English Channel and found that predicted distributions based on recent ocean warming had not been fulfilled. Hydrodynamic modeling and field recruitment surveys indicated that flow barriers have prevented the poleward range shifts of these species. Furthermore, in the coarser, correlative analysis of 31 shifting marine species presented in Box 1, there was a trend towards faster poleward spread in species inhabiting areas of primarily poleward - as opposed to equatorward - flow. This pattern, although preliminary, suggests a potential relationship between flow direction and poleward spread rate.

Beyond impeding dispersal, equatorward and downslope flows could be eroding adaptive capacities of species, reducing the efficacy of interrelated mechanisms for coping with changing climate. Geographic variation in environmental conditions and, thus, selection pressure on physiological climate tolerances can lead to beneficial local adaptation when it parallels projected climate changes (Jump and Peńuelas 2005). Species with populations that experience futuristic (e.g. warmer) conditions could be predisposed to adapt to novel climates; in other words, equatorward populations may contain individuals adapted to contemporary temperature ranges that will become the future conditions at more poleward locations. Depending on the rate of climate change, gene flow and propagule dispersal from these more tolerant populations could promote persistence 1) by 'rescuing' increasingly mal-adapted populations, 2) by re-seeding locations left vacant due to climate-related mortality, and/or 3) by colonizing new areas at the expanding range margin. Conversely, in the presence of counterproductive flow, downstream locations 


\section{Box 1.}

To address where and when (i.e. for which types of species) directional flows have inhibited poleward range shifts and could do so increasingly in the future, we would need an unbiased sample of species' range dynamics across a variation of flow regimes. Unfortunately, such a dataset does not exist at present, given biases against publishing 'negative' results or those countering the popular paradigm of poleward shifts (Stewart 2010) as well as the uneven distribution of historical and current monitoring efforts. However, despite such biases, some intriguing patterns emerged in a comparison of flow direction and spread direction for recently-shifting marine species.

A database of marine species that had experienced range shifts was reported in Sorte et al. (2010; note that non-shifting species were excluded both explicitly and via likely non-publication). Here, I expanded this database to examine the relationship between flow and spread for all outer-coast benthic species that were identified via our earlier systematic review of the literature (see Sorte et al. 2010 for search terms and expanded species information). The NOAA Ocean Surface Current Analysis (NOAA 2012), which provides current data spatially averaged at $2^{\circ}$ latitude and longitude intervals, was queried across the years 1993-2003 to determine whether the north-south element of the averaged currents was poleward or equatorward at each species' initial range boundary. I then related this dominant flow direction to direction and speed of poleward spread for each species.

I found that most - 26 out of 31 - species in this dataset inhabited areas of predominantly equatorward flow, including the northeast and west coasts of the US, western Europe, and western South America. With this locational bias and a likely publishing bias towards poleward spread, it is perhaps not surprising that about half $(55 \%)$ of species included were spreading poleward against equatorward flows. This percentage is slightly less than the $63 \%$ that would be expected by chance based on the percentage of species inhabiting areas of equatorward flow (84\%) and spreading poleward (75\%; Sorte et al. 2010); nonetheless, it clearly indicates the ability of physical and biotic processes to allow species to shift against the flow. For example, Zacherl et al. (2003) suggested that current reversals combined with increasing temperatures could have allowed the subtidal gastropod Kelletia kelletii, the species in this dataset that shifted fastest against the flow, to overcome both dispersal and temperature limitation, allowing colonization and establishment of poleward habitats.

Overall, an examination of spread rates showed that the range boundaries of species in poleward flows tended to shift towards the poles twice as fast on average as range boundaries of species in equatorward flows (5.6 $\pm 3.0 \mathrm{SE}$ vs $2.7 \pm 2.1 \mathrm{SE} \mathrm{km} \mathrm{year}{ }^{-1}$, respectively). Although limited by low sample sizes, particularly for species inhabiting locations of poleward flow, this pattern begs further study. Slower relative spread rates associated with equatorward flows might suggest that whereas species are not prevented from shifting against the prevailing currents, in some cases, equatorward flows could hamper species' abilities to keep pace with poleward shifts in climate.

Comparison of spread direction and poleward spread rate for shifting marine species inhabiting locations of poleward versus equatorward flow. For references and expanded species information, see Sorte et al. (2010).

\begin{tabular}{|c|c|c|c|c|c|}
\hline Taxon & Species & Location & Flow direction ${ }^{+}$ & Spread direction $^{+}$ & Poleward spread rate $\left(\mathrm{km} \text { year }{ }^{-1}\right)^{\ddagger}$ \\
\hline \multirow[t]{2}{*}{ Coral } & Acropora cervicornis & Florida, USA & $P$ & $P$ & 6.3 \\
\hline & Acropora palmata & Florida, USA & $\mathrm{P}$ & $P$ & 9.7 \\
\hline Gastropod & Gibbula umbilicalis & Scotland, UK & $P$ & $P$ & 3.2 \\
\hline \multirow[t]{2}{*}{ Crab } & Eurypanopeus depressus & Argentina & $\mathrm{P}$ & $\mathrm{P}$ & 13.2 \\
\hline & Panopeus meridionalis & Argentina & $\mathrm{P}$ & $\mathrm{E}$ & -4.6 \\
\hline \multirow[t]{13}{*}{ Seaweed } & Chondrus crispus & Portugal & $\mathrm{E}$ & $\mathrm{P}$ & 3.7 \\
\hline & Codium adhaerens & Portugal & $E$ & $P$ & 1.2 \\
\hline & Desmarestia ligulata & Portugal & $E$ & $P$ & 1.4 \\
\hline & Dumontia contorta & Portugal & $\mathrm{E}$ & $\mathrm{P}$ & 1.3 \\
\hline & Fucus serratus & Spain & $E$ & $P$ & 5.0 \\
\hline & Halopithys incurva & Portugal & $E$ & $P$ & 9.7 \\
\hline & Himanthalia elongata & Portugal & $\mathrm{E}$ & $\mathrm{P}$ & 4.5 \\
\hline & Hypnea musciformis & Portugal & $E$ & $P$ & 5.5 \\
\hline & Padina pavonica & Portugal & $\mathrm{E}$ & $\mathrm{P}$ & 3.8 \\
\hline & Palmaria palmata & Portugal & $\mathrm{E}$ & $\mathrm{P}$ & 7.3 \\
\hline & Pelvetia canaliculata & Portugal & $E$ & $\mathrm{P}$ & 5.0 \\
\hline & Sargassum flavifolium & Portugal & $\mathrm{E}$ & $\mathrm{P}$ & 12.1 \\
\hline & Valonia utricularis & Portugal & $\mathrm{E}$ & $\mathrm{P}$ & 4.0 \\
\hline \multirow[t]{3}{*}{ Gastropod } & Kelletia kelleti & California, USA & $E$ & $\mathrm{P}$ & 32.5 \\
\hline & Lottia orbignyi & Chile & $\mathrm{E}$ & $\mathrm{P}$ & 13.8 \\
\hline & Scurria viridula & Chile & $\mathrm{E}$ & $\mathrm{P}$ & 5.9 \\
\hline Barnacle & Tetraclita rubescens & California, USA & $\mathrm{E}$ & $\mathrm{P}$ & 22.0 \\
\hline \multirow[t]{5}{*}{ Seaweed } & Ahnfeltia plicata & Portugal & $E$ & $E$ & -6.7 \\
\hline & Bifurcaria bifurcata & Portugal & $\mathrm{E}$ & $\mathrm{E}$ & -5.2 \\
\hline & Desmarestia aculeata & Portugal & $E$ & $E$ & -4.6 \\
\hline & Fucus vesiculosus & Portugal & $\mathrm{E}$ & $E$ & -3.2 \\
\hline & Halidrys siliquosa & Portugal & $\mathrm{E}$ & $\mathrm{E}$ & -1.8 \\
\hline Chiton & Enoplochiton niger & Chile & $\mathrm{E}$ & $\mathrm{E}$ & -7.7 \\
\hline \multirow[t]{3}{*}{ Gastropod } & Echinolittorina peruviana & Chile & $\mathrm{E}$ & $\mathrm{E}$ & -14.9 \\
\hline & Fissurella crassa & Chile & $E$ & $E$ & -8.9 \\
\hline & Thais haematoma & Chile & $\mathrm{E}$ & $E$ & -15.9 \\
\hline
\end{tabular}

${ }^{+} \mathrm{P}=$ poleward, $\mathrm{E}=$ equatorward; ${ }^{\ddagger}$ negative values indicate rates of spread in the opposing (equatorward) direction. 
with the potential to harbor warm-adapted populations which may be necessary for the maintenance of the equatorward boundary, if it is set by temperature - could be swamped by gene flow from upstream populations, speeding up range contractions (Kirkpatrick and Barton 1997, Kawecki and Holt 2002, Sexton et al. 2009, 2011, Pringle et al. 2011). The ability of such beneficial adaptations to arise and persist in downstream locations will depend on the relationship between flow rate and the strength of natural selection, with the persistence of adaptations and populations more likely at lower flow rates (Byers and Pringle 2006, Pringle and Wares 2007).

Asymmetric flows may, therefore, be counterproductive to persistence by limiting evolutionary and ecological processes that could buffer species from detrimental climatic changes. Thus, whereas poleward flows might be expected to facilitate range expansions that parallel shifting climates (Fig. 1a), equatorward flows could be limiting to poleward redistribution for some species (Fig. 1b). This leads to a general prediction that assemblages existing in locations of predominantly equatorward and down-slope flows may face disproportionate losses of diversity as warming continues.

\section{Conditions influencing upstream redistribution}

Although flow patterns can limit dispersal, examples from the far (Vermeij 1991) and recent past (Box 1; McQuaid and Phillips 2000, Gilg and Hilbish 2003, Pringle et al. 2011) make it clear that asymmetry in dispersal is not absolute. For the many populations persisting in areas with directional flows, the maintenance of stable range boundaries requires some level of upstream dispersal (Müller 1982, Speirs and Gurney 2001). Furthermore, it is intuitively and mathematically evident that the conditions in which maintenance of a population's distribution is possible are also those at which the trajectory of the upstream range boundary switches from retreating to advancing (Pachepsky et al. 2004, Lutscher et al. 2010). What is unknown, then, is not whether upstream spread is possible but, rather, whether species' strategies for maintaining stable range boundaries in advective environments will allow them to shift fast enough to keep pace with changing climate. Refining hypotheses about the role of asymmetric flows in driving population persistence will, therefore, require an understanding of the degree to which physical and organismal characteristics permit counter-current redistribution and how these characteristics will, themselves, be altered under climate change (Table 1).

\section{Flow and landscape characteristics}

Heterogeneity in flow patterns can be important in allowing propagule transport contrary to average flow. In models simulating the extreme situations of entirely symmetric versus asymmetric metapopulations (i.e. populations linked by dispersal), persistence was not possible under complete asymmetry; reciprocal, bidirectional connectivity between populations was required for metapopulation persistence (Vuilleumier and Possingham 2006). At the population level, viability was low for all of the following: isolated populations, populations functioning solely as propagule sources, and those functioning as strong propagule sinks (Vuilleumier and Possingham 2006).

Deviations from predominant flow directions occur both in space and time, increasing the scope of possible dispersal trajectories (Gaylord and Gaines 2000, McQuaid and Phillips 2000, Byers and Pringle 2006). On the south coast of South Africa, monthly net displacement of passive particles in surface currents was $50-90 \%$ of total displacement, with lower values indicating months of greatest variation in wind direction and, thus, flow variation (i.e. when particles spent more time traveling contrary to the dominant flow direction; McQuaid and Phillips 2000). In this case, flow reversals occurred at a temporal scale of less than one month; however, in some systems, seasonal flow reversals are known. For example, in a tropical Panamanian forest, strong trade winds blow equatorward during the spring dry season while wet season winds are slower and less directional (Wright et al. 2008). Similarly, whereas ocean currents off of the US west coast flow primarily equatorward during the summer months, a poleward counter-current forms during the winter months and, on smaller temporal and spatial scales, during summer upwelling events (Huyer et al. 1989).

The ephemerality of appropriate flow conditions could make landscape patterns of appropriate habitat particularly important. If an individual propagule succeeds in dispersing upstream into the newly suitable range, it may be challenged in finding a place to colonize and establish (Marshall et al. 2010). Furthermore, initially following climatic shifts, individuals may be required to weather relatively high levels of climate variability in their expanded range, and population persistence during unfavorable periods can be as important as dispersal ability for determining redistribution potential (Early and Sax 2011). Similarly, the existence of 'stepping stone' locations or populations has emerged as critical for dispersal to promote persistence under changing conditions (Treml et al. 2008).

\section{Organismal characteristics}

Flow and landscape patterns interact with organismal characteristics to promote or restrict redistribution, and adaptation appears to favor life-history traits that allow species to take advantage of variation in flow patterns (Shanks and Eckert 2005, Byers and Pringle 2006). Species that produce an increased number of dispersive propagules and reproduce over longer intervals may 'hedge bets' effectively to disperse during periods of greatest flow variation (Aitken et al. 2008, Byers and Pringle 2006). Selection may also promote adaptation for specifically releasing propagules during the most variable time periods: the annual peak of spawning for 89 marine invertebrates with planktonic larvae on the US west coast corresponded with the month of greatest current flow variation (Reitzel et al. 2004, Byers and Pringle 2006).

Propagule duration relates to dispersal distance for some species (Shanks et al. 2003, Shanks 2009, Selkoe and Toonen 2011); thus, redistribution ability under climate change is likely to vary across species because distinct life-history strategies involve different amounts of time spent in aerial transport or in the plankton. However, long propagule durations appear to be both advantageous and disadvantageous for redistribution in directional flow, 


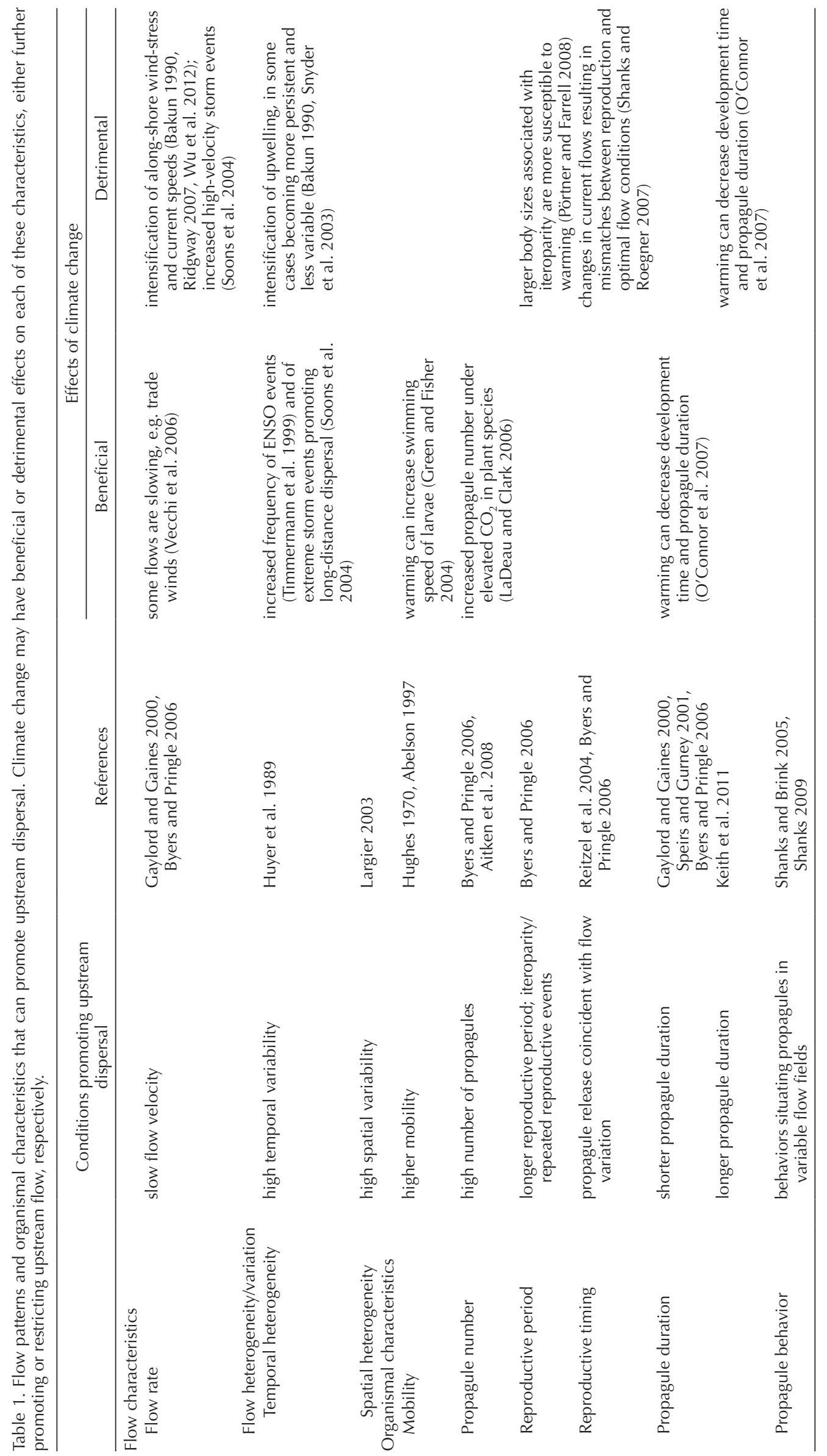


complicating location- and species-specific predictions. In advective systems, the likelihood of an individual propagule dispersing contrary to the dominant currents is predicted to decrease as propagule duration increases since the odds favor downstream flow (Gaylord and Gaines 2000, Speirs and Gurney 2001, Byers and Pringle 2006). However, a longer propagule dispersal window increased connectivity between patches in a simulated metapopulation (Treml et al. 2008). In addition, longer propagule durations are required for rare, long-distance dispersal events, quantified by Keith et al. (2011) as the number of hydrodynamic dispersal barriers that could be breached relative to pelagic larval duration.

\section{Conditions affected by climate change}

Climate change interacts with both flow characteristics and biological traits which, themselves, modify distribution potential (Table 1). Recent analyses indicate that poleward flowing western boundary currents have warmed worldwide, two to three times faster than the average global surface temperature (Ridgway 2007, Wu et al. 2012), and that this intensification could be increasing poleward propagule dispersal and enhancing range shifts (Banks et al. 2010). Similar intensification has been predicted for the Eastern Pacific Boundary Current (Bakun 1990) whereas trade winds are predicted to diminish due to the weakening of temperature and pressure gradients (Vecchi et al. 2006). Climate change can also influence temporal frequency and spatial intensity of flow variation. For example, on the US west coast where coastal currents flow equatorward on average, the poleward Davidson current that develops seasonally becomes even more pronounced on the multi-year scale of ENSO events (Huyer et al. 1989). Given that ENSO events have been predicted to increase in frequency under climate change (Timmermann et al. 1999), there may be a concomitant increase in the potential for poleward propagule delivery towards increasingly suitable habitats (Sorte et al. 2001).

At the species level, demographic traits are often sensitive to climatic conditions, with alterations related to warming, elevated $\mathrm{CO}_{2}$ levels, and changes in precipitation patterns. Whether climatic changes will lead to beneficial or detrimental modifications - in, for example, reproductive output, growth rates (which may influence time to maturity and/or size-dependent reproductive output), or survival - depends on the particular species and magnitude of climate change (Sorte et al. 2013). Development time, in particular, is often strongly temperature-dependent, and increased temperatures could, thus, decrease propagule duration for many species (Byers and Pringle 2006, O'Connor et al. 2007).

It seems clear that life-history strategies will be key determinants of species' abilities to cope with changing climate via redistribution (Nathan et al. 2011, Fordham et al. 2012). However, there are several indications that relative advantages of particular strategies will be contextdependent, varying with flow and future interactions with climate change. For example, the relationship between propagule duration and upstream redistribution potential might differ based on the local climate velocity (Loarie et al. 2009, Burrows et al. 2011): whereas shorter propagule durations and dispersal distances might be favored under low climate velocities, increasing rates of climate change could intensify the need for low-frequency, long-distance dispersal events that are more likely with broadly-dispersing species. Mechanistic simulation models, incorporating, for this example, ecophysiological data on temperaturedependent propagule duration along with both directional flow and shifting climate, could aid in predicting when and where particular life-history strategies will increase or decrease resistance to climate change (Berg et al. 2010).

\section{Predicting persistence: future research considerations}

Directional flows can and have limited the dispersal, invasive spread, and redistribution under climate change of species across systems and worldwide. At the same time, wind- and water-dispersed species do not disperse completely passively - any activity that allows a propagule to change vertical flow fields can alter its dispersal trajectory (Shanks et al. 2003, Pineda et al. 2007, Shanks 2009) - and some level of upstream dispersal is necessary for the maintenance of contemporary range boundaries. To date, there is a paucity of data available to address whether the processes described above that prevent downstream displacement in advective environments are sufficient to permit not just 'maintenance' but upstream 'advancement' of range boundaries, allowing species to keep pace with shifting climates. Although retrospective and prospective studies suggest that average spread rates will fall short of those required to track climate changes (Davis 1989, Nathan et al. 2011), species' maximal spread rates are often unknown (Davis 1989), and some species have moved significantly faster than temperature isoclines (Parmesan 2006, Sorte et al. 2010, Chen et al. 2011). Given the knowledge gaps identified above, I aim for this discussion to serve as a point of departure for further research.

Future research would ideally include an analytical study of the conditions allowing persistence in areas where flow and climate shifts are parallel versus non-parallel (as in Fig. 1). Second, it would be beneficial to expand on the quantitative analysis presented in Box 1, including by increasing the sample size as well as hindcasting flow direction and variability and relating these local conditions to dispersal distances. Third, large-scale analyses, and the field-testing of analytical conclusions, would be impossible without continued and increased field monitoring of species' ranges and environmental conditions. Comparative studies would ideally include empirical observations of range dynamics for species inhabiting opposing flow fields. For example, pinpointing characteristics that promote versus restrict redistribution across flow conditions could be accomplished by comparing range-shift success and spread rates between species dispersing in poleward and equatorward flowing western and eastern boundary currents. The benefits to adopting a mechanistic approach are demonstrated by an increasing number of analyses that have successfully combined historical ecology, empirical physiology and field ecology, and predictive modeling to hindcast and forecast ecological patterns (Tobin et al. 2008, Wethey and Woodin 2008, Jones et al. 2010).

Further refinement of the broad-scale analyses suggested above will require accounting for spatial and temporal 
variability of conditions on the scale at which they limit individual organismal and population processes, such as survival and population growth, respectively (Helmuth et al. 2006). For example, organismal survival can relate more strongly to microhabitat temperatures than to averages across available habitat (Huey 1991), and regional climate patterns can create a mosaic of temperatures across a latitudinal gradient (Helmuth et al. 2002), begging refinement of predictions beyond simply equating poleward redistribution with persistence potential per se. Similarly, while initial attempts to relate flow characteristics to redistribution success might be conducted using coarse measures of flow and spread direction (e.g. as in Box 1), better monitoring of local flow patterns and range-shift timelines should increasingly allow for more realistic predictions.

The identification of potential mechanistic relationships between location- and species-specific characteristics could help to frame hypotheses about ecological patterns and changes across geographic scales. Vulnerability to extinction associated with flow patterns could be considered together with the expectation that risk of climate change will be greater in regions, for example, of high climatechange velocities (Loarie et al. 2009, Burrows et al. 2011) or where species are already living nearer to their tolerance limits (e.g. because temperature limits distribution or species are strongly locally adapted; Deutsch et al. 2008, Somero 2010).

Forecasting the probability of species persistence versus extinction is critical for discussing possible pre-emptive measures, such as habitat conservation and managed relocation (Lawler 2009). In determining conservation strategies, it may be helpful to divide species into four categories based on decreasing persistence ability: 1) species that can, via tolerance, acclimation, and/or adaptation, persist in situ; 2) species that must redistribute to persist but whose dispersal is independent of flow (e.g. very mobile species); 3) species that must redistribute and whose dispersal is flow-dependent; 4) species that cannot persist in situ but which are unable to disperse even under ideal conditions. Conservation strategies might differ between the two latter groups for which persistence appears to require human intervention. Species in category 4 would be dependent on human relocation whereas management strategies could be enacted to support the natural redistribution of species in category 3 , such as ensuring access to dispersal corridors and networks of suitable habitat on scales over which propagules would be expected to disperse (Carr et al. 2003, Lawler 2009). In summary, considering flow patterns in tandem with climate and range projections has the potential to improve predictions of persistence for the earth's many non-moving foundation and basal species as well as the communities and food webs that they support.

Acknowledgements - Discussions with D. Blumenthal, M. Bracken, R. Etter and R. Hannigan, and their feedback on this or an earlier version of this manuscript, are much appreciated. This work was sponsored by 'Establishment of the Northeast Coastal Watershed Geospatial Data Network', a grant funded by the Dept of Energy (DOE ER64982).

\section{References}

Abelson, A. 1997. Settlement in flow: upstream exploration of substrata by weakly swimming larvae. - Ecology 78: 160-166.

Aitken, S. N. et al. 2008. Adaptation, migration or extirpation: climate change outcomes for tree populations. - Evol. Appl. 1: 95-111.

Anderson, B. J. et al. 2009. Dynamics of range margins for metapopulations under climate change. - Proc. R. Soc. B 276: 1415-1420.

Bakun, A. 1990. Global climate change and intensification of coastal ocean upwelling. - Science 247: 198-201.

Banks, S. C. et al. 2010. Genetic structure of a recent climate change-driven range extension. - Mol. Ecol. 19: 2011-2024.

Berestycki, H. et al. 2009. Can a species keep pace with a shifting climate? - Bull. Math. Biol. 71: 399-429.

Berg, M. P. et al. 2010. Adapt or disperse: understanding species persistence in a changing world. - Global Change Biol. 16: $587-598$.

Bradbury, I. R. and Snelgrove, P. V. R. 2001. Contrasting larval transport in demersal fish and benthic invertebrates: the roles of behaviour and advective processes in determining spatial pattern. - Can. J. Fish. Aquat. Sci. 58: 811-823.

Brown, J. K. and Hovmøller, M. S. 2002. Aerial dispersal of pathogens on the global and continental scales and its impact on plant disease. - Science 297: 537-541.

Burrows, M. T. et al. 2011. The pace of shifting climate in marine and terrestrial ecosystems. - Science 334: 652-655.

Byers, J. E. and Pringle, J. M. 2006. Going against the flow: retention, range limits and invasions in advective environments. - Mar. Ecol. Progr. Ser. 313: 27-41.

Carr, M. H. et al. 2003. Comparing marine and terrestrial ecosystems: implications for the design of coastal marine reserves. - Ecol. Appl. 13: S90-S107.

Carson, H. S. et al. 2011. Evaluating the importance of demographic connectivity in a marine metapopulation. - Ecology 92: 1972-1984.

Caughley, G. et al. 1988. The edge of the range. - J. Animal Ecol. 57: 771-785.

Chen, I.-C. et al. 2011. Rapid range shifts of species associated with high levels of climate warming. - Science 333: 1024-1026.

Davis, M. B. 1989. Lags in vegetation response to greenhouse warming. - Climate Change 15: 75-82.

Davis, H. G. et al. 2004. Pollen limitation causes an Allee effect in a wind-pollinated invasive grass (Spartina alterniflora). - Proc. Natl Acad. Sci. USA 101: 13804-13807.

Deutsch, C. A. et al. 2008. Impacts of climate warming on terrestrial ectotherms across latitude. - Proc. Natl Acad. Sci. USA 105: 6668-6672.

Dullinger, S. et al. 2012. Extinction debt of high-mountain plants under twenty-first-century climate change. - Nature Climate Change 2: 619-622.

Early, R. and Sax, D. F. 2011. Analysis of climate paths reveals potential limitations on species range shifts. - Ecol. Lett. 14: $1125-1133$.

Etterson, J. R. and Shaw, R. G. 2001. Constraints to adaptive evolution in response to global warming. - Science 294: 151-154.

Fordham, D. A. et al. 2012. Plant extinction risk under climate change: are forecast range shifts along a good indicator of species vulnerability to global warming? - Global Change Biol. 18: 1357-1371.

Gaston, K. J. 2009. Geographic range limits: achieving synthesis. - Proc. R. Soc. B 276: 1395-1406.

Gaylord, B. and Gaines, S. D. 2000. Temperature or transport? Range limits in marine species mediated solely by flow. - Am. Nat. 155: 769-789. 
Gienapp, P. et al. 2008. Climate change and evolution: disentangling environmental and genetic responses. - Mol. Ecol. 17: $167-178$.

Gilg, M. R. and Hilbish, T. J. 2003. The geography of marine larval dispersal: coupling genetics with fine-scale physical oceanography. - Ecology 84: 2989-2998.

Green, B. S. and Fisher, R. 2004. Temperature influences swimming speed, growth and larval duration in coral reef fish larvae. - J. Exp. Mar. Biol. Ecol. 299: 115-132.

Grosholz, E. 1996. Contrasting rates of spread for introduced species in terrestrial and marine systems. - Ecology 77: 1680-1686.

Gross, S. J. and Price, T. D. 2000. Determinants of the northern and southern range limits of a warbler. - J. Biogeogr. 27: 869-878.

Hayden, B. P. and Dolan, R. 1976. Coastal marine fauna and marine climates of the Americas. - J. Biogeogr. 3: 71-81.

Helmuth, B. S. et al. 2002. Climate change and latitudinal patterns of intertidal thermal stress. - Science 298: 1015-1017.

Helmuth, B. et al. 2005. Biophysics, physiological ecology, and climate change: does mechanism matter? - Ann. Rev. Physiol. 37: 177-201.

Helmuth, B. et al. 2006. Living on the edge of two changing worlds: forecasting the responses of rocky intertidal ecosystems to climate change. - Annu. Rev. Ecol. Evol. Syst. 37: 373-404.

Hershey, A. E. et al. 1993. Stable isotopes resolve the drift paradox for Baetis mayflies in an Arctic river. - Ecology 74: 2315-2325.

Howe, H. F. and Smallwood, J. 1982. Ecology of seed dispersal. - Annu. Rev. Ecol. Syst. 13: 201-228.

Huey, R. B. 1991. Physiological consequences of habitat selection. - Am. Nat. 137: S91-S115.

Hughes, D. 1970. Some factors affecting drift and upstream movements of Gammarus pulex. - Ecology 51: 301-305.

Huyer, A. et al. 1989. Poleward flow in the California Current System. - In: Neshyba, S. J. et al. (eds), Poleward flows along eastern ocean boundaries. Springer, pp. 144-159.

IPCC 2007a. Intergovernmental Panel on Climate Change Climate Change 2007: the physical science basis. - Cambridge Univ. Press.

IPCC 2007b. Intergovernmental Panel on Climate Change. Climate Change 2007: impacts, adaptation and vulnerability. - Cambridge Univ. Press.

Jackson, S. T. and Sax, D. F. 2009. Balancing biodiversity in a changing environment: extinction debt, immigration credit and species turnover. - Trends Ecol. Evol. 25: 153-160.

Jones, S. J. et al. 2010. Rising environmental temperatures and biogeography: poleward range contraction of the blue mussel, Mytilus edulis L., in the western Atlantic. - J. Biogeogr. 37: 2243-2259.

Jump, A. S. and Peñuelas, J. 2005. Running to stand still: adaptation and the response of plants to rapid climate change. - Ecol. Lett. 8: 1010-1020.

Kawecki, T. J. and Holt, R. D. 2002. Evolutionary consequences of asymmetric dispersal rates. - Am. Nat. 160: 333-347.

Keith, S. A. et al. 2011. Individualistic species limitations of climate-induced range expansions generated by meso-scale dispersal barriers. - Divers. Distrib. 17: 275-286.

Kinlan, B. P. and Gaines, S. D. 2003. Propagule dispersal in marine and terrestrial environments: a community perspective. - Ecology 84: 2007-2020.

Kintisch, E. 2008. Impacts research seen as next climate frontier. - Science 322: 182-183.

Kirkpatrick, M. and Barton, N. H. 1997. Evolution of a species' range. - Am. Nat. 150: 1-23.

LaDeau, S. L. and Clark, J. S. 2006. Elevated $\mathrm{CO}_{2}$ and tree fecundity: the role of tree size, interannual variability, and population heterogeneity. - Global Change Biol. 12: 822-833.

Largier, J. L. 2003. Considerations in estimating larval dispersal distances from oceanographic data. - Ecol. Appl. 13: S71-S89.

Lawler, J. J. 2009. Climate change adaptation strategies for resource management and conservation planning. - Ann. N.Y. Acad. Sci. 1162: 79-98.

Lenoir, J. et al. 2008. A significant upward shift in plant species optimum elevation during the 20th century. - Science 320: 1768-1771.

Loarie, S. R. et al. 2009. The velocity of climate change. - Nature 462: 1052-1057.

Lutscher, F. et al. 2010. Population persistence in the face of advection. - Theor. Ecol. 3: 271-284.

Maclean, I. M. D. and Wilson, R. J. 2011. Recent ecological responses to climate change support predictions of high extinction risk. - Proc. Natl Acad. Sci. USA 108: 12337-12342.

Marshall, D. J. et al. 2010. Phenotype-environment mismatches reduce connectivity in the sea. - Ecol. Lett. 13: 128-140.

McLachlan, J. S. et al. 2005. Molecular indicators of tree migration capacity under rapid climate change. - Ecology 86: 2088-2098.

McQuaid, C. D. and Phillips, T. E. 2000. Limited winddriven dispersal of intertidal mussel larvae: in situ evidence from the plankton and the spread of the invasive species Mytilus galloprovincialis in South Africa. - Mar. Ecol. Progr. Ser. 201: 211-220.

Moritz, C. et al. 2008. Impact of a century of climate change on small-mammal communities in Yosemite National Park, USA. - Science 322: 261-264.

Müller, K. 1982. The colonization cycle of freshwater insects. - Oecologia 52: 202-207.

Muñoz, J. et al. 2004. Wind as a long-distance dispersal vehicle in the southern hemisphere. - Science 304: 1144-1147.

Nathan, R. et al. 2011. Spread of North American wind-dispersed trees in future environments. - Ecol. Lett. 14: 211-219.

NOAA (National Oceanic and Atmospheric Association). 2012. OSCAR (Ocean Surface Current Analysis - Real time) Project Office. Earth and Space Research, Seattle. < www.oscar.noaa. gov/ $>$.

Normand, S. et al. 2009. Importance of abiotic stress as a rangelimit determinant for European plants: insights from species responses to climatic gradients. - Global Ecol. Biogeogr. 18: 437-449.

O'Connor, M. I. et al. 2007. Temperature control of larval dispersal and the implications for marine ecology, evolution, and conservation. - Proc. Natl Acad. Sci. USA 104: 1266-1271.

Pacala, S. W. et al. 1996. Forest models defined by field measurements: estimation, error analysis and dynamics. - Ecol. Monogr. 66: 1-43.

Pachepsky, E. et al. 2004. Persistence, spread and the drift paradox. - Theor. Popul. Biol. 67: 61-73.

Parmesan, C. 2006. Ecological and evolutionary responses to recent climate change. - Annu. Rev. Ecol. Evol. Syst. 37: 637-669.

Parolo, G. and Rossi, G. 2008. Upward migration of vascular plants following a climate warming trend in the Alps. - Basic Appl. Ecol. 9: 100-107.

Pineda, J. et al. 2007. Larval transport and dispersal in the coastal ocean and consequences for population connectivity. - Oceanography 20: 22-39.

Pörtner, H. O. and Farrell, A. P. 2008. Physiology and climate change. - Science 322: 690-692.

Potapov, A. B. and Lewis, M. A. 2004. Climate and competition: the effect of moving range boundaries on habitat invasibility. - Bull. Math. Biol. 66: 975-1008.

Pounds, J. A. et al. 1999. Biological response to climate change on a tropical mountain. - Nature 398: 611-615. 
Pringle, J. M. and Wares, J. P. 2007. Going against the flow: maintenance of alongshore variation in allele frequency in a coastal ocean. - Mar. Ecol. Progr. Ser. 335: 69-84.

Pringle, J. M. et al. 2011. Asymmetric dispersal allows an upstream region to control population structure throughout a species' range. - Proc. Natl Acad. Sci. USA 108: 15288-15293.

Reitzel, A. M. et al. 2004. Relationships between spawning date and larval development time for benthic marine invertebrates: a modeling approach. - Mar. Ecol. Progr. Ser. 280: 13-23.

Ridgway, K. R. 2007. Long-term trend and decadal variability of the southward penetration of the East Australian Current. - Geophys. Res. Lett. 34: L13613, doi: 10.1029/2007GL 030393.

Roughgarden, J. et al. 1988. Recruitment dynamics in complex life cycles. - Science 241: 1460-1466.

Selkoe, K. A. and Toonen, R. J. 2011. Marine connectivity: a new look at pelagic larval duration and genetic metrics of dispersal. - Mar. Ecol. Progr. Ser. 436: 291-305.

Sexton, J. P. et al. 2009. Evolution and ecology of species range limits. - Annu. Rev. Ecol. Evol. Syst. 40: 415-436.

Sexton, J. P. et al. 2011. Gene flow increases fitness at the warm edge of a species' range. - Proc. Natl Acad. Sci. USA 108: 11704-11709.

Shanks, A. L. 2009. Pelagic larval duration and dispersal distance revisited. - Biol. Bull. 216: 373-385.

Shanks, A. L. and Brink, L. 2005. Upwelling, downwelling, and cross-shelf transport of bivalve larvae: test of a hypothesis. - Mar. Ecol. Progr. Ser. 302: 1-12.

Shanks, A. L. and Eckert, G. L. 2005. Population persistence of California Current fishes and benthic crustaceans: a marine drift paradox. - Ecol. Monogr. 75: 505-524.

Shanks, A. L. and Roegner, G. C. 2007. Recruitment limitation in Dungeness crab populations is driven by variation in atmospheric forcing. - Ecology 88: 1726-1737.

Shanks, A. L. et al. 2003. Propagule dispersal distance and the size and spacing of marine reserves. - Ecol. Appl. 13: S159-S169.

Snyder, M. A. et al. 2003. Future climate change and upwelling in the California Current. - Geophys. Res. Lett. 30: 1823, doi: 10.1029/2003GL017647.

Somero, G. N. 2010. The physiology of climate change: how potentials for acclimatization and genetic adaptation will determine the 'winners' and 'losers'. - J. Exp. Biol. 213: 912-920.

Soons, M. B. et al. 2004. Determinants of long-distance seed dispersal by wind in grasslands. - Ecology 85: 3056-3068.

Sorte, C. J. et al. 2001. Larval dynamics of the sand crab, Emerita analoga, off the central Oregon coast during a strong El Niño period. - J. Plankton Res. 23: 939-944.

Sorte, C. J. B. et al. 2010. Marine range shifts and species introductions: comparative spread rates and community impacts. - Global Ecol. Biogeogr. 19: 303-316.

Sorte, C. J. B. et al. 2011. Geographic variation in temperature tolerance as an indicator of potential population responses to climate change. - J. Exp. Mar. Biol. Ecol. 400: 209-217.
Sorte, C. J. B. et al. 2013. Poised to prosper? A cross-system comparison of climate change effects on native and non-native species performance. - Ecol. Lett. doi: 10.1111/ele.12017.

Speirs, D. C. and Gurney, W. S. C. 2001. Population persistence in rivers and estuaries. - Ecology 82: 1219-1237.

Stewart, G. 2010. Meta-analysis in applied ecology. - Biol. Lett. 6: $78-81$.

Thomas, C. D. et al. 2004. Extinction risk from climate change. - Nature 427: 145-148.

Timmermann, A. et al. 1999. Increased El Niño frequency in a climate model forced by future greenhouse warming. - Nature 398: 694-697.

Tobin, P. C. et al. 2008. Historical and projected interactions between climate change and insect voltinism in a multivoltine species. - Global Change Biol. 14: 951-957.

Treml, E. A. et al. 2008. Modeling population connectivity by ocean currents, a graph-theoretic approach for marine conservation. - Landscape Ecol. 23: 19-36.

Vanschoenwinkel, B. et al. 2008. Any way the wind blows frequent wind dispersal drives species sorting in ephemeral aquatic communities. - Oikos 117: 125-134.

Vecchi, G. A. et al. 2006. Weakening of tropical Pacific atmospheric circulation due to anthropogenic forcing. - Nature 441: 73-76.

Vermeij, G. J. 1991. Anatomy of an invasion: the trans-Arctic interchange. - Paleobiology 17: 281-307.

Visser, M. E. 2008. Keeping up with a warming world; assessing the rate of adaptation to climate change. - Proc. R. Soc. B 275: 649-659.

Vuilleumier, S. and Possingham, H. P. 2006. Does colonization asymmetry matter in metapopulations? - Proc. R. Soc. B 273: 1637-1642.

Wares, J. P. et al. 2001. A comparative study of asymmetric migration events across a marine biogeographic boundary. - Evolution 55: 295-306.

Warren, M. S. et al. 2001. Rapid responses of British butterflies to opposing forces of climate and habitat change. - Nature 414: 65-69.

Wethey, D. S. and Woodin, S. A. 2008. Ecological hindcasting of biogeographic responses to climate change in the European intertidal zone. - Hydrobiologia 606: 139-151.

Wright, S. J. et al. 2008. Understanding strategies for seed dispersal by wind under contrasting atmospheric conditions. - Proc. Natl Acad. Sci. USA 105: 19084-19089.

Wu, L. et al. 2012. Enhanced warming over the global subtropical western boundary currents. - Nature Climate Change 2: 161-166.

Zacherl, D. et al. 2003. The limits to biogeographical distributions: insights from the northward range extension of the marine snail, Kelletia kelletii (Forbes, 1852). - J. Biogeogr. 30: 913-924.

Zardi, G. I. et al. 2011. The combination of selection and dispersal helps explain genetic structure in intertidal mussels. - Oecologia 165: 947-958. 